\title{
Effect of pen size, group size, and stocking density on activity in freestall-housed dairy cows
}

\author{
E. Telezhenko, M. A. G. von Keyserlingk, A. Talebi, and D. M. Weary ${ }^{1}$ \\ Animal Welfare Program, Faculty of Land and Food Systems, The University of British Columbia, 2357 Main Mall, Vancouver, V6T 1Z4, Canada
}

\begin{abstract}
The purpose was to determine the effects of the physical dimensions of the pen and group size and stocking density on cow activity. Cows (randomly assigned to 4 groups of 6 animals each) were tested in pens with 24 or 12 lying places and in groups with 12 or 6 cows. All groups were tested in each of the 4 treatments with treatment order allocated using a $4 \times 4$ Latin square. The distance moved and the number of movements were calculated using 5-min scan sampling of video recordings over a 48 -h period. Time spent lying down, number of lying bouts, and the duration of each lying bout were recorded using activity sensors. Displacements at the feed bunk were assessed by continuous analysis of video for $3 \mathrm{~h}$ after the delivery of the fresh feed in the afternoon. Cows moved greater distances when kept in a large versus small pens (330.2 vs. $270.1 \pm 11.6 \mathrm{~m} / \mathrm{d}$; mean $\pm \mathrm{SE}$ ), irrespective of group size. Cows moved more often when kept in the larger pen (21.3 vs. $19.2 \pm$ $0.63 \%$ of scans). The time spent lying down decreased when density increased (59.1 vs. $55.8 \pm 2.3 \%$ of scans at $25 \%$ and $100 \%$ stocking, respectively). Treatment had no effect on the number of displacements at the feed bunk. Physical dimensions of the pen play an important role in how much cows move, and stocking density affects lying time.
\end{abstract}

Key words: cattle, locomotion, exercise, lying time

\section{INTRODUCTION}

The amount of space provided to intensively housed animals is one of the most contentious issues for members of the public concerned about farm animal welfare (Vanhonacker et al., 2009). Space per animal can affect building cost, but keeping animals in crowded conditions can lead to behavioral and health problems (Bowell et al., 2003). Better understanding the effects of space availability on animals is important in address-

Received September 9, 2011.

Accepted February 3, 2012.

${ }^{1}$ Corresponding author: dan.weary@ubc.ca ing these concerns and will help with improvements in barn design and management. Previous work has linked higher densities to increased frequency of aggression, behavioral problems, and reduced performance in cattle (beef cattle: Fisher et al., 1997; dairy cattle: Fregonesi and Leaver, 2002; Huzzey et al., 2006). Differences in animal densities are not controlled by a single factor but rather by the combination of group size and pen size. All 3 factors may affect animals, making research in this area challenging (Christman and Leone, 2007).

More than 3 decades of research has considered the effects of stocking density on various measures of dairy cow behavior (Friend et al., 1977; Hill et al., 2009), but no research to date has attempted to separate the effects of group size, pen size, and stocking density. The availability of space may be important for maintaining adequate locomotor activity. Previous work has showed that exercise improves blood circulation, develops the muscular system, and promotes health in dairy cows (Gustafson, 1993; Davidson and Beede, 2009). Increased walking also reduces blood levels of NEFA, potentially reducing the risk of metabolic and digestive disorders (Adewuyi et al., 2006). Some authors have speculated that locomotor activity in cattle may increase at higher densities, because increased competition may force cows to move to access resources or escape competitors (Bøe and Færevik, 2003). Others have argued that animals may decrease locomotor activity when housed at higher densities because less space is available and cows are unable to escape the aggressive behavior of other cows (Estevez et al., 2007). To the best of our knowledge, no study to date has tested the effect of stocking density, space availability, or group size on locomotor activity in dairy cows. Thus, the objective was to examine the effect of these factors on activity of lactating dairy cows housed in a freestall barn.

\section{MATERIALS AND METHODS}

\section{Animals and Management}

Cows were housed in a freestall barn at The University of British Columbia Dairy Education and Research Centre (Agassiz, British Columbia, Canada) and cared 
for according to the guidelines published by the Canadian Council on Animal Care (CCAC, 2009). Four "large" pens were used; each could be separated into 2 "small" pens (Figure 1). Animals were fed a TMR for ad libitum consumption provided twice daily (from 0500 to $0600 \mathrm{~h}$ and from 1500 to $1600 \mathrm{~h}$ ), and feed was pushed up 4 times/d. Cows had ad libitum access to water from a self-filling trough and were milked twice daily starting at approximately 0500 and $1700 \mathrm{~h}$ in a double-12 parallel milking parlor.

\section{Design}

Twenty-four Holstein cows in the second half of their lactation (214.4 \pm 14.6 DIM), confirmed pregnant and without signs of clinical lameness, were assigned pseudo-randomly (balancing for parity) to 4 groups of 6 animals each (each group contained 2 cows of each parity class: 1, 2, and 3 and older). Each group of 6 cows was subjected to the 4 treatments, each for $7 \mathrm{~d}$, with treatment order allocated using a $4 \times 4$ Latin-square design. Treatments were (1) large pen, small group; (2) large pen, large group; (3) small pen, small group; and (4) small pen, large group, varying stocking density from 1 cow to 4 stalls (i.e., 25\%) to 1 cow to 1 stall (100\%). Characteristics of the 4 treatments, including the resulting stocking density, are in Table 1.

To create a large group, 6 nonexperimental cows were added. Two constant groups of the 6 nonexperimental cows of similar parity composition and confirmed pregnant were used. None of the nonexperimental groups were mixed with the same experimental group more than once. The TMR was distributed evenly along the feed bunk such that each cow had $0.6 \mathrm{~m}$ of feed access in all conditions.

The addition and removal of the nonexperimental cows may have disrupted behavior, so the first $5 \mathrm{~d}$ of each treatment period were not analyzed. Experimental cows were followed continuously during the last 2 $\mathrm{d}$ of each of the $4 \mathrm{wk}$ using $16 \mathrm{WV}-\mathrm{BP} 330$ cameras (Panasonic, Osaka, Japan; 2 cameras per experimental pen) and Geovision GV-1480-16 digital video record-

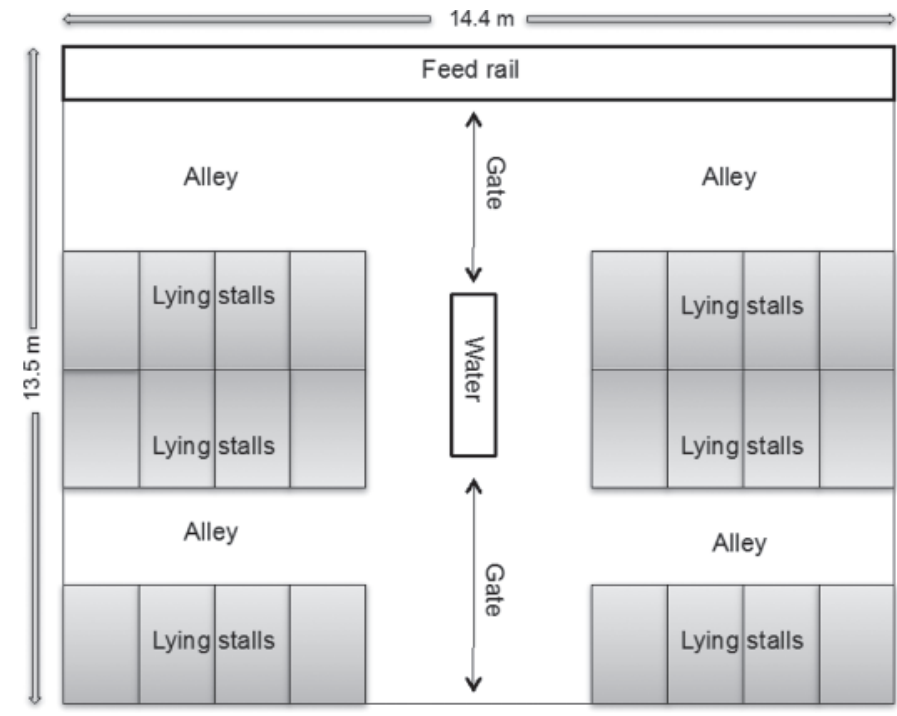

Figure 1. Schematic of a "large" test pen. Large pens could be separated using gates to form 2 "small" pens that shared a single water trough. Each of the small pens contained 12 freestalls configured in 3 rows. Two rows faced each another and were open at the front (head-to-head) with a bed length of $2.40 \mathrm{~m}$. The third row of freestalls faced a chasing alley (separated by a low concrete wall); these stalls were $0.30 \mathrm{~m}$ longer. Stalls were bedded with $0.4 \mathrm{~m}$ of sand, measured $1.20 \mathrm{~m}$ wide center to center, with a neck rail $1.14 \mathrm{~m}$ above the stall surface. Each pen had $7.20 \mathrm{~m}$ of linear feed bunk space available via a pendulous feed rail. The alley closest to the feed bunk was $3.60 \mathrm{~m}$ wide and the alley between the freestall rows was $2.5 \mathrm{~m}$ wide. Flooring throughout the pen (including the cross-over alley) was grooved concrete. Alleys were cleaned 6 times/d with automatic scrapers, and the cross-over alley manually scraped twice daily.

ing system (version 8.3, GeoVision Inc., Corona, CA). Red lights $(100 \mathrm{~W})$ were positioned above the pens to facilitate video recording at night. During milking, observations were suspended from the time the first animal left the pen and restarted when the last animal returned to the pen.

The experimental pen was divided into a grid of 1.8 $\times 1.8$-m cells using landmarks on the barn surface visible on the video recordings. Each cow's position was recorded from video using instantaneous scan sampling once every 5 min. If a cow was standing on the border

Table 1. Characteristics of the 4 treatments tested to assess pen and group size and stocking density of dairy cows

\begin{tabular}{|c|c|c|c|c|c|c|}
\hline \multirow[b]{2}{*}{ Treatment } & \multirow[b]{2}{*}{$\begin{array}{l}\text { Number } \\
\text { of freestalls }\end{array}$} & \multirow[b]{2}{*}{$\begin{array}{l}\text { Number } \\
\text { of cows }\end{array}$} & \multirow[b]{2}{*}{$\begin{array}{l}\text { Total walking } \\
\text { area }\left(\mathrm{m}^{2}\right)\end{array}$} & \multicolumn{2}{|c|}{ Stocking density } & \multirow[b]{2}{*}{$\begin{array}{c}\text { Alley } \\
\text { length (m) }\end{array}$} \\
\hline & & & & $\begin{array}{l}\text { Cows per } \\
\text { freestall }\end{array}$ & $\begin{array}{l}\text { Walking area } \\
\text { per cow }\left(\mathrm{m}^{2}\right)\end{array}$ & \\
\hline Large pen, large group & 24 & 12 & 120 & 0.50 & 10 & 14.4 \\
\hline Small pen, small group & 12 & 6 & 60 & 0.50 & 10 & 7.2 \\
\hline Small pen, large group & 12 & 12 & 60 & 1.00 & 5 & 7.2 \\
\hline
\end{tabular}


between adjacent cells, she was assigned to the location containing the largest portion of her body. If the division was equal, location was assigned to the cell containing the cow's head.

The minimum number of cells required to cross between successive observations was calculated, taking into account the location of crossover alleys and the presence of stall rows that prevented cows from traveling in a direct line. The number of squares was multiplied by $1.8 \mathrm{~m}$ (the size of each square) to calculate the distance in meters. Distance moved $(\mathrm{m} / \mathrm{d})$ was calculated by summing these observations. A cow was classified as having moved when her position in the current scan differed from that in the previous scan. Movement (\%) was calculated as the number of scans in which the cow changed grid locations (in relation to the previous scan) as a percentage of the total number of scans when the cow was in the test pen.

The time cows spent lying down was recorded using activity sensors (IceTag and IceTag 3D 1.008, IceRobotics Ltd., Edinburgh, UK) attached to a rear leg. Lying time (\%) was calculated by dividing the time spent lying by the total time spent in the test pen. The number of lying bouts (no./d) and average bout duration $(\mathrm{min} / \mathrm{d})$ were calculated from the IceTag data. Data from the IceTag sensors were downloaded weekly, and the position was changed (left to right leg or vice versa) to prevent leg lesions.

Displacements (no. $/ 3 \mathrm{~h}$ ) at the feed bunk were recorded using continuous observation of video for $3 \mathrm{~h}$ after fresh feed delivery during the last day of each treatment. A displacement was recorded when a cow completely withdrew her head from the feed bunk immediately following a push or butt from another cow.

\section{Statistical Analysis}

To validate the use of 5 -min scan sampling intervals for distance moved, observations were repeated at 1-min intervals for all animals for $5 \mathrm{~h}$ (between 1015 and 1515 h) during $1 \mathrm{~d}$ of observation. The limits of agreement between the different scan intervals for estimation of distance traveled were estimated as described by Bland and Altman (2003).

Response measures were analyzed with PROC MIXED (version 9.1.3, SAS Institute Inc., Cary, NC) using pen averages as the experimental unit. The effect of treatment $(3 \mathrm{df})$ was tested in a model that included week (3 df) specified as a repeated measure and group specified as subject, using an auto-regressive co-variance structure. Specified contrasts were used to test the effects of pen size (i.e., the 2 large pen treatments vs. the 2 small pen treatments; $1 \mathrm{df}$ ), group size (i.e., the
2 large group treatments vs. the 2 small group treatments; $1 \mathrm{df}$ ), and stocking density (i.e., small group in the large pen vs. large group in the small pen; $1 \mathrm{df}$ ). The combined effect of pen and group size at equidensity was tested by contrasting the small group in the small pen versus large group in the large pen (1 df).

\section{RESULTS}

\section{Distance Moved}

Distance moved, as estimated using 5-min scans, was correlated with the estimate from 1-min scans ( $\mathrm{r}=$ $0.97, P<0.001)$, although 5 -min scans slightly underestimated distances (Figure 2). We observed a positive relationship $(\mathrm{r}=0.79, P<0.001)$ between the degree of underestimation and the distance traveled. The average underestimation of distance measured with 5-min scans was $12.4 \%$ ( $\mathrm{SD}=9.66 \%$; $95 \%$ confidence limits -31.3 and $+6.6 \%)$.

Cows moved greater distances $(P=0.004)$ when kept in large versus small pens (approximately 330 vs. 270 $\mathrm{m} / \mathrm{d}$; Table 2), and no effect of group size was observed. The effect of density was significant $(P=0.011)$, but this effect appeared driven by pen size; when tested at equidensity, cows moved more in the large pen (with a

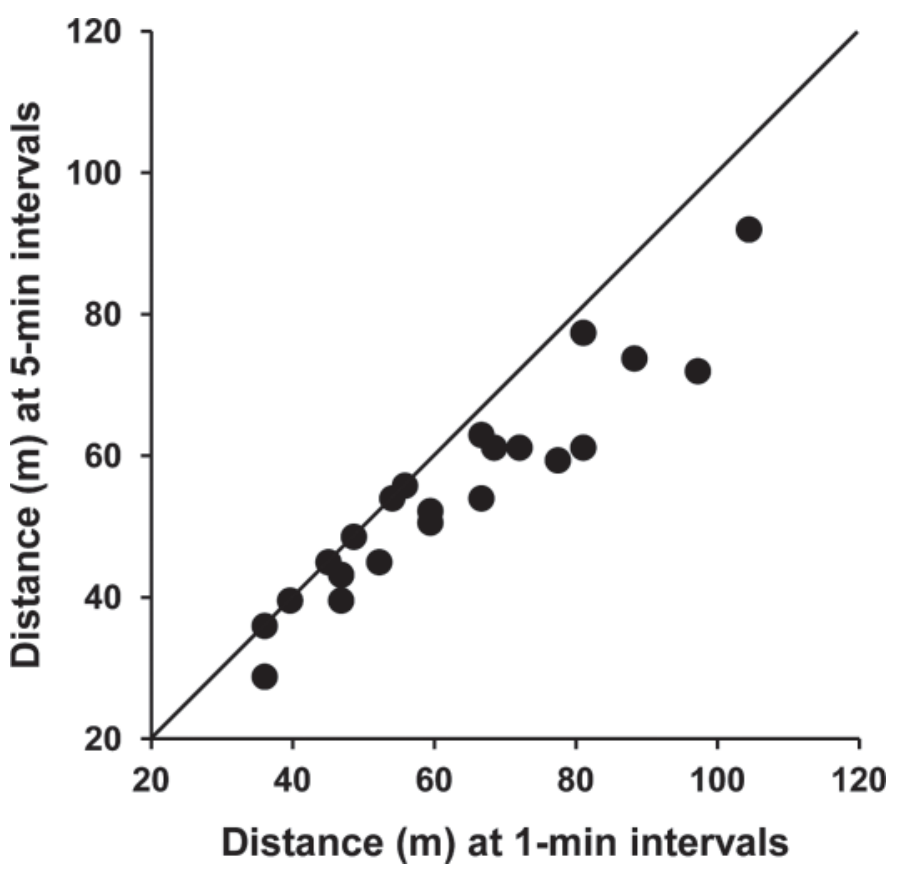

Figure 2. Scatter plot of distance moved recorded at 5-min versus 1-min intervals, in relation to the line of equality. Observations were made for all animals for $5 \mathrm{~h}$ between morning and afternoon milking during $1 \mathrm{~d}$ of observation. The line of equality illustrates perfect agreement between the 2 measures. 
Table 2. Least squares means $( \pm \mathrm{SE})$ distance moved, percentage of movements, percentage of time lying, frequency of lying bouts, lying bout duration, and displacements for each of the 4 treatments

\begin{tabular}{|c|c|c|c|c|c|c|c|c|}
\hline \multirow[b]{2}{*}{ Variable } & \multicolumn{2}{|c|}{ Large pen } & \multicolumn{2}{|c|}{ Small pen } & \multicolumn{4}{|c|}{$P$-value ${ }^{1}$} \\
\hline & $\begin{array}{l}\text { Large group; } \\
\text { density: } 50 \%\end{array}$ & $\begin{array}{l}\text { Small group; } \\
\text { density: } 25 \%\end{array}$ & $\begin{array}{l}\text { Large group; } \\
\text { density: } 100 \%\end{array}$ & $\begin{array}{l}\text { Small group; } \\
\text { density: } 50 \%\end{array}$ & $\begin{array}{l}\text { Pen } \\
\text { size }\end{array}$ & $\begin{array}{l}\text { Group } \\
\text { size }\end{array}$ & Density & Equidensity \\
\hline Distance $(\mathrm{m} / \mathrm{d})$ & $330.5 \pm 13.5$ & $330.0 \pm 13.5$ & $278.0 \pm 13.5$ & $262.3 \pm 13.5$ & 0.004 & 0.43 & 0.011 & 0.010 \\
\hline Movements (\%) & $21.2 \pm 0.8$ & $21.4 \pm 0.8$ & $18.9 \pm 0.8$ & $19.6 \pm 0.8$ & 0.016 & 0.31 & 0.006 & 0.11 \\
\hline Lying (\%) & $57.8 \pm 2.3$ & $59.1 \pm 2.3$ & $55.8 \pm 2.3$ & $57.2 \pm 2.3$ & 0.14 & 0.10 & 0.015 & 0.70 \\
\hline Lying bouts (n/d) & $10.2 \pm 0.6$ & $10.1 \pm 0.6$ & $10.8 \pm 0.6$ & $10.5 \pm 0.6$ & 0.41 & 0.64 & 0.28 & 0.69 \\
\hline
\end{tabular}

${ }^{1} P$-values are for the specified contrasts testing the effect of pen size (i.e., the 2 large pen treatments versus the 2 small pen treatments), group size (i.e., the 2 large group treatments versus the 2 small group treatments), stocking density (i.e., small group in the large pen versus large group in the small pen treatments), and equidensity (i.e., small group in the small pen versus large group in the large pen).

large group; $333 \mathrm{~m} / \mathrm{d} ; P=0.010)$ than in the small pen (with a small group; $263 \mathrm{~m} / \mathrm{d}$ ).

\section{Number of Movements}

Cows moved more often $(P=0.016)$ in large pens versus small pens; cows changed grid locations in approximately $21 \%$ of observations in the large pens compared with $19 \%$ in small pens (Table 2). This measure was not affected by group size. The percentage of scans in which cows moved decreased with increasing stocking density $(P=0.006)$. This effect of density was due in part to the effect of pen size but, within both large and small pens, movements declined when density increased, suggesting that density itself was important. Moreover, the number of movements did not differ between the equidensity treatments that differed in both pen and group size.

\section{Time Spent Lying, Number of Lying Bouts, and Lying Bout Duration}

Percentage of time cows spent lying down decreased $(P=0.015)$ with increasing stocking density; at the lowest density (25\%; 1 cow per 4 stalls), cows spent almost $60 \%$ of the time available lying down compared with $56 \%$ of the time when stocked at $100 \%$ (i.e., 1 cow per stall). Pen or group size had no effect, and lying times did not differ in the 2 equidensity conditions despite differences in pen and group size (Table 2).

Treatment had no effect on the number of the lying bouts or lying bout duration.

\section{Displacements}

Cows displaced other cows at the feed bunk approximately 5 times in the 3 -h period after feeding. This number of displacements was not affected by treatment.

\section{DISCUSSION}

Cows moved greater distances when kept in larger pens, but we observed no effect of group size. To date, the effect of pen size on dairy cows has been ignored (or confounded with the effects of group size and density). Work on poultry has attempted to separate these effects (Leone and Estevez, 2008) and has shown that movements are primarily affected by enclosure size, followed by density, with little or no effect of group size. Previous work on calves has indicated that increased availability of space can trigger activity (Jensen, 1999). One reason that pen size may be more important than density or group size is that group-housed animals are able to share the space in the pen, such that even with the same number of animals per square meter, larger pens will provide more free space in which animals can move. For example, work with pigs (McGlone and Newby, 1994) has shown that the amount of free space increases with pen size even when stocking density is held constant.

In the current study, cows showed fewer movements when density increased. Work on chickens has also shown fewer movements at high stocking densities, perhaps because the other animals can act as a physical barrier (Estevez et al., 2007). In the current study, stocking never exceeded $100 \%$, and this density provided approximately $5 \mathrm{~m}^{2}$ of walking area per cow. At this density, it seems unlikely that other cows were a physical barrier to movement but the social behavior of at least some cows may have made it difficult for other cows to move freely in the pen.

Even in the largest pens used, the total distance cows moved per day was modest $(<500 \mathrm{~m}$, including the distance walked to the milking parlor). This value is at the low end of the range of distances $(0.4$ to $3 \mathrm{~km} / \mathrm{d}$ ) that have positive effects on measures of cow health, including mastitis and hoof and leg disorders (Gustafson, 
1993) and positive effects on getting up and lying down behavior (Gustafson and Lund-Magnussen, 1995). Davidson and Beede (2009) reported health benefits of exercise but walked cows in excess of $3 \mathrm{~km}$.

Lying time decreased with increasing stocking density. Earlier studies have shown that overstocking reduces lying time (Cook et al., 2005; Fregonesi et al., 2007), but little work has examined understocked pens. In the current study, none of the treatments were overstocked, perhaps explaining the relatively small differences in lying time. Even at 100\% stocking, cows spent approximately $56 \%$ of the time available lying down. This value corresponds to about $13 \mathrm{~h} / \mathrm{d}$, a value commonly associated with good stall comfort (Cook et al., 2005). To our knowledge no previous research has examined the effects of pen and group size (independent of stocking density) on lying times in dairy cows.

The number of agonistic interactions at the feed bunk was not affected by treatment. Agonistic interactions were measured only on the last day of each treatment (i.e., $7 \mathrm{~d}$ after regrouping), providing a considerable period for these interactions to stabilize (Kondo and Hurnik, 1990; von Keyserlingk et al., 2008). Also, regrouping in the current study meant joining 2 established groups (such that cows would recognize at least half of the group mates after the regrouping), and cows were kept in their familiar home pen, likely minimizing any effects of regrouping on these results. Fewer agonistic interactions at the feed bunk would normally be expected at lower densities (DeVries et al., 2004), but in the current study, stocking at the feeder was held constant across treatments by spreading TMR along the feeding area in relation to the number of cows in the pen.

Several questions remain unanswered. Broiler birds housed in larger enclosures not only traveled greater distances but also maintained larger nearest-neighbor distances and larger home ranges (Leone and Estevez, 2008); we would expect similar effects in dairy cattle. We encourage future work on how space is configured, considering factors including the ratio of pen length to pen width and perimeter length (Christman and Leone, 2007). Two-row dairy pens are much longer than they are deep, creating more feeding space, typically down the inside perimeter, than is available in the deeper 3-row pens (Bewley et al., 2001); on this basis, we expect more competition at the feed bunk in 3-row pens. Freestall pens for cows do not allow use of the entire space for locomotion as cows can only walk freely in the alleys. We suggest that future studies examine different aspects of space limitations, such as the presence of blind alleys. Finally, even the "large" pen was small relative to pens used on large commercial farms. Future studies should assess the effects of the much larger pen and group sizes increasingly found on commercial farms.

\section{ACKNOWLEDGMENTS}

We thank the staff and students at The University of British Columbia's Dairy Education and Research Centre. In particular, we thank Pierre Groenenboom for his help in developing the method for estimating travel distances. The University of British Columbia's Animal Welfare Program is funded by the Natural Sciences and Engineering Research Council's (Ottawa, ON, Canada) Industrial Research Chair Program, with industry contributions from the Dairy Farmers of Canada (Ottawa, ON, Canada), Westgen Endowment Fund (Milner, BC, Canada), Pfizer Animal Health (Kirkland, QC, Canada), BC Cattle Industry Development Fund (Kamloops, BC, Canada), the BC Milk Producers (Burnaby, BC, Canada), BC Dairy Foundation (Burnaby, BC, Canada), BC Dairy Industry Research and Education Fund (Abbotsford, BC, Canada), and Alberta Milk (Edmonton, AB, Canada).

\section{REFERENCES}

Adewuyi, A. A., J. B. Roelofs, E. Gruys, M. J. M. Toussaint, and F. J. C. M. van Eerdenburg. 2006. Relationship of plasma nonesterified fatty acids and walking activity in postpartum dairy cows. J. Dairy Sci. 89:2977-2979.

Bewley, J., R. W. Palmer, and D. B. Jackson-Smith. 2001. A comparison of free-stall barns used by modernized Wisconsin dairies. J. Dairy Sci. 84:528-541.

Bland, J. M., and D. G. Altman. 2003. Applying the right statistics: Analyses of measurement studies. Ultrasound Obstet. Gynecol. 22:85-93.

Bøe, K. E., and G. Færevik. 2003. Grouping and social preferences in calves, heifers and cows. Appl. Anim. Behav. Sci. 80:175-190.

Bowell, V. A., L. J. Rennie, G. Tierney, A. B. Lawrence, and M. Haskell. 2003. Relationship between building design, management system and dairy cow welfare. Anim. Welf. 12:547-552.

CCAC (Canadian Council on Animal Care). 2009. CCAC guidelines on: The care and use of farm animals in research, teaching and testing. CCAC, Ottawa, Ontario, Canada.

Christman, M. C., and E. H. Leone. 2007. Statistical aspects of the analysis of group size effects in confined animals. Appl. Anim. Behav. Sci. 103:265-283.

Cook, N. B., T. B. Bennett, and K. V. Nordlund. 2005. Monitoring indices of cow comfort in free-stall-housed dairy herds. J. Dairy Sci. $88: 3876-3885$.

Davidson, J. A., and D. K. Beede. 2009. Exercise training of latepregnant and nonpregnant dairy cows affects physical fitness and acid-base homeostasis. J. Dairy Sci. 92:548-562.

DeVries, T. J., M. A. G. von Keyserlingk, and D. M. Weary. 2004. Effect of feeding space on the inter-cow distance, aggression, and feeding behavior of free-stall housed lactating dairy cows. J. Dairy Sci. 87:1432-1438.

Estevez, I., I. E. Andersen, and E. Nævdal. 2007. Group size, density and social dynamics in farm animals. Appl. Anim. Behav. Sci. 103:185-204.

Fisher, A. D., A. D. Crowe, P. O'Kiely, and W. J. Enright. 1997. Growth, behaviour, adrenal and immune responses of finishing beef heifers housed on slatted floors at 1.5, 2.0, 2.5, 3.0 $\mathrm{m}^{2}$ space allowance. Livest. Prod. Sci. 51:245-254. 
Fregonesi, J. A., and J. D. Leaver. 2002. Influence of space allowance and milk yield level on behaviour, performance and health of dairy cows housed in strawyard and cubicle systems. Livest. Prod. Sci. 78:245-257.

Fregonesi, J. A., C. B. Tucker, and D. M. Weary. 2007. Overstocking reduces lying time in dairy cows. J. Dairy Sci. 90:3349-3354.

Friend, T. H., C. E. Polan, and M. L. McGilliard. 1977. Free stall and feed bunk requirements relative to behavior, production and individual feed intake in dairy cows. J. Dairy Sci. 60:108-116.

Gustafson, G. M. 1993. Effects of daily exercise on the health of tied dairy cows. Prev. Vet. Med. 17:209-223.

Gustafson, G. M., and E. Lund-Magnussen. 1995. Effect of daily exercise on the getting up and lying down behaviour of tied dairy cows. Prev. Vet. Med. 25:27-36.

Hill, C. T., P. D. Krawczel, H. M. Dann, C. S. Ballard, R. C. Hovey, W. A. Falls, and R. J. Grant. 2009. Effect of stocking density on the short-term behavioral responses of dairy cows. Appl. Anim. Behav. Sci. 117:144-149.

Huzzey, J. M., T. J. DeVries, P. Valois, and M. A. G. von Keyserlingk. 2006. Stocking density and feed barrier design affect the feeding and social behavior of dairy cattle. J. Dairy Sci. 89:126-133.
Jensen, M. B. 1999. Effects of confinement on rebounds of locomotor behaviour of calves and heifers, and the spatial preferences of calves. Appl. Anim. Behav. Sci. 62:43-56.

Kondo, S., and J. F. Hurnik. 1990. Stabilization of social hierarchy in dairy cows. Appl. Anim. Behav. Sci. 27:287-297.

Leone, E. H., and I. Estevez. 2008. Use of space in the domestic fowl: Separating the effects of enclosure size, group size, and density. Anim. Behav. 76:1673-1682.

McGlone, J. J., and B. E. Newby. 1994. Space requirements for finishing pigs in confinement: Behavior and performance while group size and space vary. Appl. Anim. Behav. Sci. 39:331-338.

Vanhonacker, F., W. Verbeke, E. Van Poucke, S. Buijs, and F. A. M. Tuyttens. 2009. Societal concern related to stocking density, pen size and group size in farm animal production. Livest. Sci. 123:16-22.

von Keyserlingk, M. A. G., D. Olenick, and D. M. Weary. 2008. Acute behavioral effects of regrouping dairy cows. J. Dairy Sci. 91:10111016 . 